\title{
List of symbols
}

\begin{tabular}{|c|c|}
\hline & itoms \\
\hline & $\begin{array}{l}\text { Distance between the mark on the witness plate and center of the det- } \\
\text { onating fuse in the Dautriche method }\end{array}$ \\
\hline$A_{\mathrm{JWL}}$ & Linear coefficient of JWL-EOS \\
\hline$B$ & $\begin{array}{l}\text { Parameter in Rothstein and Peterson's Method that is equal to } 1 \text { for } \\
\text { aromatic compounds and is otherwise given the value } 0\end{array}$ \\
\hline & Number of hydrogen atoms \\
\hline$B_{\mathrm{JWL}}$ & Linear coefficient of JWL-EOS \\
\hline BKW-EOS & Becker-Kistiakowsky-Wilson equation of state \\
\hline \multicolumn{2}{|c|}{$\begin{array}{l}\text { BKWC-EOS, BKWR-EOS and BKWS-EOS Three different parameterizations of BKW- } \\
\text { EOS }\end{array}$} \\
\hline$c$ & Number of nitrogen atoms \\
\hline$C_{\mathrm{JWL}}$ & Linear coefficient of JWL-EOS \\
\hline$C_{\text {polar }}$ & $\begin{array}{l}\text { Contribution of some specific polar or functional groups in aromatic } \\
\text { and non-aromatic } \mathrm{C}_{a} \mathrm{H}_{b} \mathrm{~N}_{c} \mathrm{O}_{d} \text { energetic compounds in the prediction } \\
\text { of the heat of detonation }\end{array}$ \\
\hline $\mathrm{C}_{\mathrm{SFG}}$ & $\begin{array}{l}\text { Contribution of some specific functional groups in aromatic } \mathrm{C}_{a} \mathrm{H}_{b} \mathrm{~N}_{c} \mathrm{O}_{d} \\
\text { energetic compounds in the prediction of the heat of detonation }\end{array}$ \\
\hline $\mathrm{C}_{\mathrm{SSP}}$ & $\begin{array}{l}\text { Contribution of some specific structural parameters in non-aromatic } \\
\mathrm{C}_{a} \mathrm{H}_{b} \mathrm{~N}_{c} \mathrm{O}_{d} \text { energetic compounds in the prediction of the heat of deto- } \\
\text { nation }\end{array}$ \\
\hline HEETAH & Thermochemical computer code \\
\hline $\mathrm{C}-\mathrm{J}$ & Chapman-Jouguet \\
\hline \multicolumn{2}{|c|}{$\begin{array}{ll}\bar{C}_{\mathrm{V}}(\text { detonation product })_{j} & \text { Molar heat capacity of } j \text { th product at constant volume } \\
\bar{C}_{\mathrm{P}}(\text { detonation product })_{j} & \text { Molar heat capacity of } j \text { th product at constant pressure }\end{array}$} \\
\hline$d$ & Number of oxygen atoms \\
\hline \multicolumn{2}{|c|}{$\begin{array}{l}D_{\text {det }}(\text { explosive charge }) \text { Detonation velocity of the explosive being tested using the } \\
\text { Dautriche method }\end{array}$} \\
\hline \multicolumn{2}{|c|}{$\begin{array}{c}D_{\text {det }}(\text { detonating fuse }) \text { Detonation velocity of the calibrated detonating fuse used in } \\
\text { the Dautriche method }\end{array}$} \\
\hline$D_{\text {det }}$ & Detonation velocity \\
\hline$D_{\text {metal }}$ & Terminal metal velocity \\
\hline$D_{\text {det,max }}$ & Theoretical maximum density of the explosive \\
\hline$D_{\text {det, } \max }^{\text {Dec }}$ & Correcting function for decreasing the value of $D_{\text {det,max }}$ \\
\hline$D_{\text {det,max }}^{\text {Inc }}$ & Correcting function for increasing the value of $D_{\mathrm{det}, \max }$ \\
\hline DOE & Design of experiments \\
\hline DSC & Differential scanning calorimetry \\
\hline & Number of fluorine atoms \\
\hline & Detonation energy per unit volume \\
\hline
\end{tabular}


$E_{\mathrm{b}}$

$E_{\mathrm{G}}$

$\sqrt{2 E_{\mathrm{G}}}$

$\left(\sqrt{2 E_{\mathrm{G}}}\right)_{\mathrm{H}-\mathrm{K}}$

$\left(\sqrt{2 E_{\mathrm{G}}}\right)_{\mathrm{K}-\mathrm{F}}$

EOS

$E_{\mathrm{S}}$

EXPLO5

$f$

$\% f_{\text {Trauzl,TNT }}$

$f_{\text {Trauzl }}^{+}$

$f_{\text {Trauzl }}^{-}$

$f_{\text {brisance,sand }}^{-}$

Gas bubble energy per kg explosives at the measuring point

Specific energy or Gurney energy (J)

Gurney velocity or Gurney constant (m/s)

Gurney velocity from Hardesty and Kennedy $(\mathrm{H}-\mathrm{K})$ method

Gurney velocity from Kamlet and Finger (K-F) method

Equation of state

Shock wave energy

Thermochemical computer code

Number of chlorine atoms

Relative power of an energetic compound with respect to TNT from the Trauzl lead block test

Correcting function for the adjustment of an underestimated value of $\% f_{\text {Trauzl,TNT }}$ obtained on the basis of the elemental composition

Correcting function for the adjustment of an overestimated value of $\% f_{\text {Trauzl,TNT }}$ obtained on the basis of the elemental composition

Correcting function for the adjustment of an overestimated value of $\% f_{\text {brisance,sand,TNT }}$ obtained on the basis of the elemental composition

$\% f_{\text {ballistic mortar,TNT }}$ Relative power an energetic compound with respect to TNT from the ballistic mortar test

$\% f_{\text {brisance,sand,TNT }}$ Relative brisance of an energetic compound with respect to TNT for sand crushing test

$\left(\% f_{\text {brisance,sand,TNT }}\right)_{\text {aluminized explosive }}$ Relative brisance of an energetic compound with respect to TNT of sand crushing test for aluminized explosives

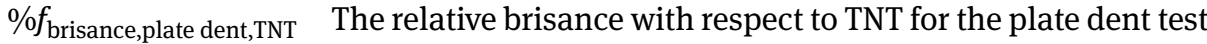

$f_{\text {Trauzl }}^{+}$

$f_{\text {brisance,sand }}^{+}$

$g$

G

GA

GIPF

$H$

$h$

$H_{\text {poducts }}$

$H_{\text {reactants }}$

$H^{\theta}$

$H(\mathrm{c})$
Correcting function for the adjustment of an underestimated value of $\% f_{\text {Trauzl,TNT }}$ obtained on the basis of the elemental composition

Correcting function for the adjustment of an underestimated value of $\% f_{\text {brisance,sand,TNT }}$ obtained on the basis of the elemental composition Number of aluminum atoms

Parameter in Rothstein and Peterson's Method that is equal to 0.4 for liquid explosives and 0 for solid explosives

Genetic algorithm

General interaction properties function

Constant pressure enthalpy

Number of moles of ammonium nitrate in an explosive composition

Enthalpy of products

Enthalpy of reactants

Enthalpy of the desired species under standard conditions $(298.15 \mathrm{~K}$ and 0.1 MPa pressure)

Enthalpy of the desired species in the condensed phase (solid or liquid) 


\begin{tabular}{|c|c|}
\hline$H^{\theta}(\mathrm{c})$ & $\begin{array}{l}\text { Enthalpy of the desired species in the condensed phase (solid or liq- } \\
\text { uid) under standard conditions ( } 298.15 \mathrm{~K} \text { and } 0.1 \mathrm{MPa} \text { pressure) }\end{array}$ \\
\hline$H(\mathrm{~g})$ & Enthalpy of the desired gaseous species \\
\hline HTPB & Hydroxy-terminated polybutadiene \\
\hline$I_{\mathrm{SP}}$ & Specific impulse \\
\hline ISPBKW & Computer code for calculation of the specific impulse using BKW-EOS \\
\hline JCZS-EOS & Jacobs-Cowperthwaite-Zwisler equation of state \\
\hline JCZS3-EOS & Jacobs-Cowperthwaite-Zwisler-3 equation of state \\
\hline JWL-EOS & Jones-Wilkins-Lee equation of state \\
\hline$k_{i}$ & Molar co-volumes of the $i$-th gaseous product \\
\hline $\mathrm{K}-\mathrm{J}$ & Kamlet-Jacob \\
\hline $\mathrm{L}$ & Length between the probes in the Dautriche method \\
\hline LASEM & Laser-induced air shock from energetic materials \\
\hline LIBS & Laser Induced Breakdown Spectroscopy \\
\hline$m$ & Mass of explosive charge \\
\hline & The ratio of the masses per unit length of the metal and the explosive \\
\hline $\bar{M}_{\text {wgas }}$ & Average molecular weight of the gaseous products \\
\hline MAPE & Mean absolute percentage error \\
\hline$\left(\frac{n_{\mathrm{Al}}}{n_{0}}\right)_{\text {LIBS }}$ & The Al/O intensity ratio determined by LIBS method \\
\hline$\left(\frac{n_{\mathrm{Al}}}{n_{0}}\right)_{\text {theory }}$ & The $\mathrm{Al} / \mathrm{O}$ intensity ratio calculated by chemical composition \\
\hline$n(\mathrm{~g})$ & Number of moles of gas involved \\
\hline$n(\mathrm{HF})$ & $\begin{array}{l}\text { Number of hydrogen fluoride molecules that can possibly be formed } \\
\text { from the available hydrogen }\end{array}$ \\
\hline$n(\mathrm{~B} / \mathrm{F})$ & $\begin{array}{l}\text { Number of oxygen atoms in addition to those necessary to form } \mathrm{CO}_{2} \\
\text { and } \mathrm{H}_{2} \mathrm{O} \text {, and/or the number of fluorine atoms in excess of those re- } \\
\text { quired to form } \mathrm{HF}\end{array}$ \\
\hline$n(\mathrm{C}=0)$ & Number of oxygen atoms doubly bonded directly to carbon \\
\hline$n(\mathrm{C}-\mathrm{O})$ & Number of oxygen atoms singly bonded directly to carbon \\
\hline$n_{\text {exp }}$ & Number of moles of explosive \\
\hline$n\left(\mathrm{NO}_{3}\right)$ & $\begin{array}{l}\text { Number of nitrate groups present as a nitrate ester, or as a nitric acid } \\
\text { salt such as hydrazine mononitrate }\end{array}$ \\
\hline$n_{j}$ & Number of moles of the $j$ th detonation product \\
\hline$n_{\text {gas }}^{\prime}$ & $\begin{array}{l}\text { Number of moles of gaseous detonation products per gram of explo- } \\
\text { sive }\end{array}$ \\
\hline$n_{\mathrm{mN}}$ & $\begin{array}{l}\text { Number of nitro groups attached to carbon in nitro compounds in } \\
\text { which } a=1\end{array}$ \\
\hline$n_{\mathrm{N}}$ & $\begin{array}{l}\text { Parameter that is equal to } 0.5 n_{\mathrm{NO}_{2}}+1.5 \text { where } n_{\mathrm{NO}_{2}} \text { is the number of } \\
\text { nitro groups attached to carbon in nitro compounds for the prediction } \\
\text { of the maximum attainable detonation pressure in which } a=l\end{array}$ \\
\hline$n_{\mathrm{NH}_{x}}$ & Number of $-\mathrm{NH}_{2}$ and $\mathrm{NH}_{4}^{+}$moieties in the energetic compounds \\
\hline$n_{\mathrm{NR}}$ & Number of $-\mathrm{N}=\mathrm{N}-$ groups or $\mathrm{NH}_{4}^{+}$cations in the explosive \\
\hline
\end{tabular}




$n_{-\mathrm{NRR}^{\prime}}$
$n_{\mathrm{NR}_{1} \mathrm{R}_{2}}$
$n_{\mathrm{Al}}^{\prime}$
$n_{\mathrm{NO}_{3} \text { salt }}^{\prime}$
$n_{1}^{0}$
$p$
$P$
$P_{\mathrm{PCA}}$
$P_{\text {cyc,nitramine }}$
$P_{\text {det }}$
$P_{\text {det,max }}$
$P_{\text {det,max,SSP }}$
$P_{\text {de }}^{\prime}$

Number of $-\mathrm{NH}_{2}, \mathrm{NH}_{4}^{+}$or $\left[\mathrm{N}_{\mathrm{N}^{\mathrm{N}}}^{\mathrm{N}}\right.$ groups

Number of $-\mathrm{NH}_{2}, \mathrm{NH}_{4}^{+}$and five membered rings with three (or four) nitrogens in any explosive, as well as five (or six) membered rings in nitramine cages

Number of moles of aluminum atoms under certain conditions

Number of moles of nitrate salt

Parameter that equals 1.0 for energetic compounds that follow the condition $d>3(a+b)$ and zero for other energetic compounds

Shock wave pressure

Pressure

Principle component analysis

Correcting function for the prediction of the heat of detonation of cyclic nitramines

Detonation pressure

Detonation pressure at the maximum loading density or theoretical maximum density of an explosive

Parameter that is equal to 1.0 for explosives which contain $\mathrm{N}=\mathrm{N}-$, $-\mathrm{ONO}_{2}, \mathrm{NH}_{4}^{+}$or $-\mathrm{N}_{3}$ in the molecular structure for the prediction of the maximum attainable detonation pressure

Correcting function that is specified for increasing the value of the maximum attainable detonation pressure on the basis of the elemental composition under certain conditions

Correcting function that is specified for decreasing the value of the maximum attainable detonation pressure on the basis of the elemental composition under certain conditions

PLS-DA Partial least squares discriminant analysis

Power Index $\left[\mathrm{H}_{2} \mathrm{O}(\mathrm{g})\right]$ Power index of an explosive if the water in the detonation products is in the gaseous state

Power Index $\left[\mathrm{H}_{2} \mathrm{O}(\mathrm{l})\right]$ Power index of an explosive if the water in the detonation products is in the liquid state

Q Heat transfer

$Q_{\text {expl }} \quad$ Heat of explosion

$Q_{\text {det }} \quad$ Heat of detonation

$Q_{\text {det }}^{\prime} \quad$ Heat of detonation

$Q_{\text {det }}\left[\mathrm{H}_{2} \mathrm{O}(\mathrm{g})\right] \quad$ Heat of detonation when $\mathrm{H}_{2} \mathrm{O}$ in the detonation products is in the gas phase

$Q_{\text {det }}\left[\mathrm{H}_{2} \mathrm{O}(\mathrm{l})\right] \quad$ Heat of detonation when $\mathrm{H}_{2} \mathrm{O}$ in the detonation products is in the liquid state

$Q_{\text {det }}\left[\mathrm{H}_{2} \mathrm{O}(\mathrm{l})\right]_{\text {aromatic }}$ Heat of detonation of an aromatic high explosive when $\mathrm{H}_{2} \mathrm{O}$ in the detonation products is in the liquid state 
$Q_{\text {det }}\left[\mathrm{H}_{2} \mathrm{O}(\mathrm{l})\right]_{\text {non-aromatic }}$ Heat of detonation of a non-aromatic high explosive when $\mathrm{H}_{2} \mathrm{O}$ in the detonation products is in the liquid state

$\mathrm{Q}_{\mathrm{H}_{2} \mathrm{O}-\mathrm{CO}_{2}} \quad$ Heat of detonation based on the " $\mathrm{H}_{2} \mathrm{O}-\mathrm{CO}_{2}$ arbitrary"

$r \quad$ Distance between the pressure gauge and charge

$R \quad$ Gas constant

$R_{1} \quad$ Nonlinear coefficient of JWL-EOS

$R_{2} \quad$ Nonlinear coefficient of JWL-EOS

$R-R_{0} \quad$ Actual radial expansion in cylinder test

rms deviation Root mean square of deviations

STP Standard Temperature and Pressure

SVR Support vector regression

$T \quad$ Temperature

$T_{b} \quad$ First pulsation period

$T_{i} \quad$ Initial temperature

$T_{\max } \quad$ Maximum temperature

$T_{\text {det }} \quad$ Detonation (explosion) temperature

$\left(T_{\text {det }}\right)_{\text {aromatic }}$ Detonation temperature of an aromatic energetic compound

$\left(T_{\text {det }}\right)_{\text {non-aromatic }}$ Detonation temperature of a non-aromatic energetic compound

TMD Theoretical maximum density

$V \quad$ Volume

$V_{0} \quad$ Volume of undetonated high explosive

$V_{\text {corr }} \quad$ Correcting function for the volume of the detonation products

$V_{\text {det }} \quad$ Volume of detonation products

$V_{\text {exp gas }} \quad$ Volume of gaseous products

$v_{\mathrm{W}} \quad$ Sound velocity in water or the acoustic velocity at the depth where the charge is positioned with allowance for the ambient water temperature

$U \quad$ Internal energy

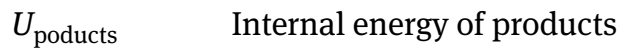

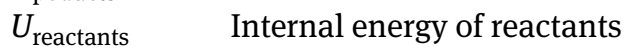

$U_{s} \quad$ Internal energy of the isentropically expanded products

$U_{0} \quad$ Internal energy of the isentropically unreacted explosive

$U$ (c) Internal energy of a specific compound in the condensed phase (solid or liquid)

$U^{\theta}$ (c) Internal energy of a specific compound in the condensed phase (solid or liquid) under standard conditions (298.15 K and 0.1 MPa pressure)

$U(\mathrm{~g}) \quad$ Internal energy of a specific gaseous compound

$V_{\text {cylinder wall Cylinder wall velocity }}$

$W \quad$ Work

$W_{\mathrm{C}-\mathrm{J}} \quad$ Velocity of gaseous products (fumes) at the $\mathrm{C}-\mathrm{J}$ point

WPHE Weight percent of high explosives

$x_{j} \quad$ Mole fraction of the $j$-th component in the explosive mixture 
$y_{i} \quad$ Mole fraction of the $i$-th gaseous product

ZMWNI Thermochemical computer code

$\Delta_{\mathrm{f}} H^{\theta}$

Standard heat of formation of the desired species in the condensed phase (solid or liquid) or gas phase

$\Delta_{\mathrm{f}} H^{\theta}(\mathrm{g}) \quad$ Standard heat of formation of a specific compound in the gas phase

$\Delta_{\mathrm{f}} H^{\theta}$ (c) Standard heat of formation of a specific compound in the condensed phase (solid or liquid)

$\Delta_{\mathrm{f}} H^{\theta}$ (detonation product) $j \quad$ Standard heat of formation of the $j$ th detonation product $\Delta H_{\mathrm{c}} \quad$ Heat of combustion

$\Delta H_{\mathrm{c}}^{\theta} \quad$ Standard heat of combustion

$\Delta U_{\mathrm{c}} \quad$ Energy of combustion

$\Delta U_{\mathrm{c}}^{\theta} \quad$ Standard energy of combustion

$\Delta V_{\text {Trauzl }}$ (energetic compound) Volume of expansion for an explosive in the Trauzl lead block test

$\Delta V_{\text {Trauzl }}(\mathrm{TNT})$ Volume of expansion for TNT in the Trauzl lead block test

$\alpha \quad$ Empirical constant of BKW-EOS

$\beta \quad$ Empirical constant of BKW-EOS

$\kappa \quad$ Empirical constant of BKW-EOS

$\delta \quad$ Dent depth

$\theta \quad$ Empirical constant of BKW-EOS

$\Omega \quad$ Oxygen balance

$\rho_{0} \quad$ Initial (loading) density $\left(\mathrm{g} / \mathrm{cm}^{3}\right)$

$\rho_{\mathrm{C}-\mathrm{J}} \quad$ Density at $\mathrm{C}-\mathrm{J}$ point $\left(\mathrm{g} / \mathrm{cm}^{3}\right)$

$\rho_{W} \quad$ Density of water at the gauge location site

$y \quad$ Adiabatic exponent

$\omega \quad$ Grüneisen coefficient or the second adiabatic coefficient

$\tau \quad$ Representative time of the process that is the time during which the pressure signal recorded drops from its maximum (at the front) to $P_{m} / e \approx 0.37 P_{m}$ where $P_{m}$ is the peak pressure of the shock wave 